\title{
Same-day physical therapy consults in an outpatient neuromuscular disease physician clinic
}

This article was published in the following Dove Press journal:

Journal of Multidisciplinary Healthcare

3 October 2016

Number of times this article has been viewed

\author{
Evan M Pucillo' \\ Nancy Christensen-Mayer ${ }^{2}$ \\ Shelly D Poole ${ }^{2}$ \\ Denise MWhitten ${ }^{2}$ \\ Danielle Freeman ${ }^{3}$ \\ Blake R Bohe ${ }^{4}$ \\ Brandon R Swensen ${ }^{3}$ \\ A Gordon Smith' \\ Nicholas E Johnson' \\ 'Department of Neurology, School \\ of Medicine, ${ }^{2}$ Department of \\ Physical Medicine \& Rehabilitation, \\ ${ }^{3}$ Outpatient Neurology, University \\ of Utah Hospitals and Clinics, \\ ${ }^{4}$ Business Support, University of Utah \\ Information Technology, Salt Lake City, \\ UT, USA
}

Correspondence: Evan M Pucillo Department of Neurology, Eccles Institute of Human Genetics, University of Utah, I5N 2030E, Room \#2270A, Salt Lake City, UT 84II2, USA

Tel + I 80I 585 I499

Email epucillo@genetics.utah.edu
Background: Team-based care has been shown to offer more comprehensive benefits to patients when compared to standard physician-based care alone in clinics for chronic conditions. However, apart from grant-funded multidisciplinary clinics, there are no reports on the usage of same-day physical therapy (PT) consults within a daily outpatient neuromuscular disease (NMD) physician clinic.

Objective: To determine the impact of same-day PT consults at the University of Utah's outpatient Clinical Neurosciences Center.

Design: A qualitative assessment and survey of patient satisfaction.

Methods: An eight question Health Insurance Portability and Accountability Act-compliant patient satisfaction survey using a 5-point Likert scale was administered. Demographic data and Press-Ganey Provider Satisfaction surveys were retrospectively collected from electronic medical records for patients receiving same-day PT encounters in the neuromuscular division over 1 year. Results: Mean (standard deviation) age was 54.22 (19.81) years for 134 patient encounters, median age was 60 years, with 76 male (57\%) and 58 female (43\%) patients. Mean Likert score for 61 self-reported patient satisfaction surveys for same-day PT consults was 4.87 (97.4\%). Press-Ganey Provider Satisfaction scores improved from $89.9 \%(\mathrm{~N}=287)$ for the year prior to $90.8 \%(\mathrm{~N}=320)$ for the corresponding year $(P=0.427)$. A total of $46(75.4 \%)$ patients have either never before received PT care or never before received PT care for their NMD, $67.4 \%$ of whom were male.

Conclusion: Same-day PT consults in an outpatient NMD physician clinic demonstrated excellent patient satisfaction and improved access to specialty care. This model could potentially be implemented in other academic medical centers to improve access to rehabilitation services for patients with NMD.

Keywords: neuromuscular therapy, neuromuscular care, team-based health care, physical therapy consults, same-day physical therapy, physician clinics, patient satisfaction

\section{Introduction}

Multidisciplinary health care has become a widely accepted model to promote teambased care and improve patient satisfaction and outcomes. ${ }^{1-8}$ Team-based care has been shown to offer more comprehensive benefits to patients when compared to standard physician-based care alone, especially in clinics involving treatment of chronic conditions, such as hypertension, diabetes, cancer care, motor neuron diseases, muscular dystrophy, and pain. ${ }^{1,2,5,7,9-12}$ Furthermore, team-based health care models contextually align with and embody the three major aims of the Centers for Medicare and Medicaid Services: better health for the population, better care for all individuals, and lower health care costs through improvement of services. ${ }^{13}$ 
Neuromuscular diseases (NMDs) are highly variable and heterogeneous in nature and often require expert care from trained specialists and allied health professionals. ${ }^{1,8,14,15}$ However, patients with NMD often do not have access to necessary therapy and allied health services. ${ }^{1,8}$ Team-based health care is an appealing model to enhance access to these services in the NMD population. To date, models exploring multidisciplinary utilization of therapy services have been found to be costeffective, improve patient satisfaction, and improve downstream revenue. ${ }^{5,8}$ Models, such as Muscular Dystrophy Association and Amyotrophic Lateral Sclerosis Association clinics aim to provide multidisciplinary health care services to unique populations and are funded through grants and charities. These clinics are often limited to regional specialized care centers and occur with more limited frequency. Our program aimed to create a sustainable model for the inclusion of same-day physical therapy (PT) consults in team-based health care. We hypothesize that many patients with NMD in the Intermountain West Region may be restricted by their geography ${ }^{16}$ and not able to access specialized therapy consults and that access to this service and patient satisfaction can be improved by implementing same-day PT consults to their physician visit when necessary.

The aims of this pilot program were to: 1) determine if self-reported patient satisfaction outcomes support the use of same-day PT consults; 2) determine if there is any relationship between geographic location and a patient's history of access to PT care; 3) determine if there is any difference in patient satisfaction for the neuromuscular division of medical providers when compared to data from the previous year; and 4) collect and analyze data on the financial viability of this model.

\section{Methods}

This pilot program was conducted over the course of 12 months (January 2015-January 2016) at the University of Utah's Clinical Neuroscience Center outpatient clinic. Patient demographic data from electronic medical records (age, sex, home of record zip code, and NMD diagnosis) were retrospectively collected for analysis. Verbal consent was obtained prior to participation in patient satisfaction surveys and all procedures were conducted in accordance with institutional guidelines.

\section{Inclusion/exclusion criteria}

Patients were included for analysis who were seen in the Neuromuscular Division of Medicine at the Clinical Neuroscience Center clinic for an outpatient physician visit and had received a same-day PT consult during the program's timeframe. Patients were excluded from our analysis if they were currently receiving PT services or if the patient was scheduled for a return visit involving a separate encounter that would preclude them from a same-day visit.

\section{Same-day PT consults}

Same-day PT consults were treated as an "add-on" visit after the physician visit had concluded. Patients were identified as having a need for PT services by a physician and were subsequently evaluated by a licensed physical therapist with experience in NMD. Each consult consisted of a single encounter, including, but not limited to, patient history, physical examination, special tests, assessment, rehabilitation diagnosis, design of a treatment plan, and any appropriate orders or referrals for durable medical equipment and/or follow-up therapy services.

\section{Patient satisfaction survey}

A self-administered eight question HIPAA-compliant patient satisfaction survey using a 5-point Likert scale (1 - strongly disagree to 5 - strongly agree) (shown in Table 1 ) was given to each patient by the physical therapist in the treatment room directly after the conclusion of the same-day PT encounter using a touch-screen tablet computer. All patients completed the survey in the treatment room in the absence of the therapist, providers, or staff to control for bias. Each patient encountered during the program's timeframe who fulfilled the inclusion criteria was asked to participate in the questionnaires for consistency and were free from any visual or physical impairment that may have impeded them from doing so.

\section{Press-Ganey Provider Satisfaction}

Retrospective provider satisfaction data were collected for Press-Ganey surveys of patient satisfaction for all neuromuscular division providers for the year prior to implementing the program (January 2014-January 2015), and were also collected for the year that coincided with the same-day PT consult pilot program (January 2015-January 2016) for comparison.

\section{Financial sustainability and downstream impact}

All billing and downstream revenue for procedures and therapeutic services recorded at the University of Utah Hospitals and Clinics, Department of Neurology, Orthopedics Center, and Physical Medicine and Rehabilitation Clinics was retrospectively captured for analysis on patients receiving same-day PT consults.

\section{Data analysis}

Descriptive statistics were used to summarize patient characteristics and survey responses. A two-tailed paired $t$-test 
Table I Patient satisfaction results

\begin{tabular}{|c|c|c|c|}
\hline Question item & $\begin{array}{l}5 \text { - Strongly } \\
\text { agree } \mathrm{N}(\%)\end{array}$ & $\begin{array}{l}\text { 4- Agree } \\
\text { N (\%) }\end{array}$ & $\begin{array}{l}\text { Mean Likert } \\
\text { score }\end{array}$ \\
\hline $\begin{array}{l}\text { QI. I am satisfied to have had same-day PT access during my visit } \\
\text { with the physician. }\end{array}$ & $52(83.87)$ & $9(14.52)$ & 4.85 \\
\hline Q2. I had a positive experience with my physical therapist today. & $54(88.5)$ & $7(11.5)$ & 4.88 \\
\hline $\begin{array}{l}\text { Q3. My immediate physical therapy needs were met today or I was } \\
\text { provided the necessary follow-up care. }\end{array}$ & $38(62.3)$ & $23(37.7)$ & 4.62 \\
\hline Q4. My wait time to see the physical therapist was acceptable. & 35 (57.4) & $26(42.6)$ & 4.57 \\
\hline Q5. The physical therapist educated me about my disease or condition.* & $33(54.1)$ & $26(42.6)$ & 4.51 \\
\hline $\begin{array}{l}\text { Q6. The information provided by the physical therapist was easy for } \\
\text { me to understand. }\end{array}$ & $4 \mathrm{I}(67.2)$ & $20(32.8)$ & 4.67 \\
\hline Q7. I received information on how to make a follow-up appointment.* & $43(70.4)$ & $17(27.8)$ & 4.69 \\
\hline Q8. I would recommend this service for a friend or family member. & $55(90.1)$ & $6(9.83)$ & 4.90 \\
\hline
\end{tabular}

Note: *Two respondents on question 5 and one respondent on question 7 indicated a score of " 3 - neither agree nor disagree".

Abbreviation: PT, physical therapy.

was performed to determine significance between variables and $P$-values $<0.05$ were considered significant.

\section{Results}

\section{Patient characteristics}

Patient demographic data are provided in Table 2. Mean ( \pm standard deviation) age was $54.22( \pm 19.81)$ years, the median age was 60 years, with 76 male $(56.7 \%)$ and 58 female $(43.3 \%)$ patients. The geographic distance from the clinic to the patients' home zip code is shown in Table 2. A total of $50(37.3 \%)$ of patients seen with NMD had to travel $>40$ miles to access our neuromuscular care, and 39 $(29.1 \%)$ traveled $>60$ miles. The most commonly encountered NMD diagnoses in our same-day PT consult program were as follows, $\mathrm{N}(\%)$ : muscular dystrophies, including myotonic, duchenne, limb-girdle, and fascioscapulohumeral, 32 (23.9\%); chronic inflammatory demyelinating polyneuropathy and/or other neuropathies, 27 (20.1\%); weakness, falls, balance impairments, and/or abnormality of gait, $23(17.2 \%)$ inflammatory myopathies and/or inclusion-body myositis, 19 (14.2\%); Charcot-Marie-Tooth disease, 17 (12.7\%); motor neuron diseases 8 (5.9\%); and movement disorders, 6 (4.5\%).

\section{Patient satisfaction survey}

A total of 134 unique same-day PT consult encounters were included for retrospective analysis. A total of 61 (45.5\%) patients completed the same-day PT consult satisfaction survey, with 33 (54.1\%) male and 28 (45.9\%) female patients. A summary of these results and a copy of the complete satisfaction questionnaire items can be found in Table 1. The aggregate Likert score for the eight-question satisfaction survey was 4.71 (94.2\%). Mean Likert score for two satisfaction question items was 4.875 (97.4\%) (Q1. "I am satisfied to have
Table 2 Patient characteristics

\begin{tabular}{ll}
\hline $\mathrm{N}$ & 134 \\
Mean age (years) & 54.22 \\
Age (SD) & $19.8 \mathrm{I}$ \\
Median age (years) & 60 \\
\hline Sex & $\mathbf{n}(\%)$ \\
\hline Female & $58(43.3)$ \\
Male & $76(56.7)$ \\
\hline Distance from University of Utah (miles) & $\mathbf{n}(\%)$ \\
\hline $0-20$ & $65(48.5)$ \\
$21-40$ & $19(14.2)$ \\
$4 I-60$ & $11(8.2)$ \\
$60+$ & $39(29.1)$ \\
\hline
\end{tabular}

Abbreviation: SD, standard deviation.

had same-day PT access during my visit with the physician"; Q8. "I would recommend this service for a friend or family member"). A total of $61(100 \%)$ of respondents scored either a " 4 - agree" or a "5 - strongly agree" on all but two question items (Q5 and Q7) (Table 1). Our results observed a mean Likert score of 4.91 for males and 4.93 for females on satisfaction questions items Q1 and Q8, and there were no significant differences found in satisfaction responses between sexes $(P=0.354)$.

At the end of each satisfaction survey was one supplemental question: Question 9. "Have you received physical therapy prior to this visit? If so, was it for the same or a different condition?" Results for each response with sex-specific mean are reported as follows, $\mathrm{N}(\%)$ : "No, this was my first time receiving physical therapy", 25 (40.9\%) with males reporting 17/25 (68\%); "I have received physical therapy before for this condition", 15 (24.6\%) with females reporting 8/15 (53.3\%); and "I have received physical therapy before, but for a different condition", $21(34.4 \%)$ with males reporting $14 / 21(66.7 \%)$. A total of $46(75.4 \%)$ patients who were 
surveyed report having either never before received PT care or never received PT care for their NMD, 31/46 (67.4\%) of whom were male.

\section{Press-Ganey Provider Satisfaction results}

A total of 287 Press-Ganey Provider Satisfaction surveys were collected for Neuromuscular Division of Medicine providers for the year prior to implementing this program, January 2014-January 2015. Overall satisfaction was $89.9 \%$, with a total response rate of $17.5 \%$. Also, $91.3 \%$ reported they would recommend the provider and $92.8 \%$ would recommend the practice. Comparatively, a total of 320 PressGaney Provider Satisfaction surveys were collected for the year that coincided with the same-day PT consult program, January 2015-January 2016, with a total response rate of $18.3 \%$. Overall satisfaction for this group was $90.8 \%$, and the difference between the two groups was not significant $(P=0.427)$. In all, $93.5 \%$ reported they would recommend the provider and $94.0 \%$ would recommend the practice to a friend or family member. Overall, $100 \%$ of patient encounters reported that they would recommend same-day PT consults to a friend or family member, $a+6 \%$ difference between groups. The largest improvement in patient satisfaction between the previous and current year was observed in the likelihood of recommending the practice, $+1.2 \%$.

\section{Financial sustainability}

Downstream revenue was calculated for 134 patient electronic medical records, receiving same-day PT encounters. A total of 109 unique encounters were identified that met criteria for financial analysis of downstream revenue. For these 109 same-day PT encounters, the average cost of a visit was $48 \%$ of the average downstream charges, with an average charge of $\$ 900$, and the average reimbursement rate was $37 \%$ per encounter, yielding a net negative margin. Fully adjusted margin for salary and facility charges was not captured in this analysis as they had already been taken into account for the physician visit.

\section{Discussion}

Overall, this study shows that patient satisfaction is very high for those patients having access to same-day PT consults after their physician visit and supports continued use of this model. This program also demonstrated that a modest portion, greater than one-third, of NMD patients are separated by considerable distance from access to specialized NMD care. Our results also indicate that a substantial majority of patients surveyed ( $>75 \%$ ) reported having never before received PT care for their NMD, of whom a considerable number were male. This pilot suggests that large hospitals and academic medical centers with specialized care and resources could employ this model for patients with NMD to improve access for those who may be disconnected from expert care due to their geographical location. Those patients who received same-day PT consults after their neuromuscular physician visit were more satisfied and more likely to recommend the service. However, our financial data suggest that this model is not yet financially sustainable and the host clinic incurs a net cost. Further study is necessary to evaluate this model's transferability and financial sustainability at other institutions.

This study does have limitations. Potential limitations may include a modest sample size. A cross-sectional analysis was conducted at a single point in time during a patient's care and our population may have varied from new diagnosis to advanced stages of disease. The population represented in our data may not necessarily be representative of all NMD diagnoses as disease severity can vary greatly and NMDs are inherently heterogeneous in nature. Also, our population may not represent other traditional outpatient neuromuscular clinics in other regions, as muscular dystrophies may be overrepresented in our data due to the prevalence of facioscapulohumeral dystrophy seen in Utah. ${ }^{17}$

Potential bias may exist as the therapist administered the survey tool at the conclusion of the visit and only $45.5 \%$ of our total number of same-day PT consult encounters completed the online satisfaction survey tool. In comparison, however, an average of only $17.9 \%$ of patients seen by the Neuromuscular Division of Medicine had completed Press-Ganey Provider Satisfaction surveys. Fluctuations in patient volume were observed during holidays and at times when providers were attending professional conferences and meetings, which could have affected the amount of data collected.

Likewise, many patients seen for their physician visit were either currently receiving PT, had recently received and completed PT, or did not have an immediately identified need for PT. Therefore, these patients did not meet our inclusion criteria and were not referred for a same-day PT consult nor were they included in our analysis. Our data could be overrepresentative of patients with decreased access to care, as these more complex patients may have a greater need of services due to scarcity of local resources. Thus, our data may also be biased given the geographic nature of the rural 
Intermountain West Region and may not be applicable to other regions across the US. ${ }^{16}$ One study demonstrated an analysis of travel times and distances to health care in which the Intermountain West Region holds a larger portion of highly rural areas when compared to other regions of the US. ${ }^{16}$

Overall, same-day PT consults in an outpatient physician clinic is a novel and easily reproducible model, is feasible, and our preliminary data suggest excellent patient satisfaction and increased access to patients who have never before seen a PT for their NMD. In the future, this model could potentially be utilized for tele-rehabilitation consults in an effort to provide PT consults and advice to patients in rural and remote partner clinic sites. This may help provide rural patients more frequent access to readily available teleconference rehabilitation consultations while decreasing their travel burden and decreasing costs to the university. This model could be easily implemented in other outpatient physician clinics, which may help provide better community outreach and access to services for those patients coming from a great distance or when their disability limits their means to travel. Large academic medical centers with access to the latest technology, resources, and experienced personnel could feasibly incorporate same-day PT consults services to optimize patient care for those who are separated by large geographic distances from the care they require.

\section{Acknowledgments}

We would like to thank all of the staff and faculty at the University of Utah's Clinical Neurosciences Center for their enthusiastic support of this study, especially the physicians and fellows in the Neuromuscular Division of Medicine and their support team, including Mark Bromberg, Russell Butterfield, Yoonhee Choi, Kelsey Juster, Summer Gibson, Peter Hannon, Noah Kolb, Rob Singleton, Ligia Onofrei, Deborah Eve Foster, Allison Taylor, Abby Smart, Amber Harkin, and Cassie Kuhn.

\section{Disclosure}

The authors report no conflicts of interest in this work.

\section{References}

1. Cup EH, Pieterse AJ, Hendricks HT, van Engelen BG, Oostendorp RA, van der Wilt GJ. Implementation of multidisciplinary advice to allied health care professionals regarding the management of their patients with neuromuscular diseases. Disabil Rehabil. 2011;33(9):787-795.

2. Houle SK, Chatterley T, Tsuyuki RT. Multidisciplinary approaches to the management of high blood pressure. Curr Opin Cardiol. 2014;29(4):344-353.

3. Saxena N, Rizk DV. The interdisciplinary team: the whole is larger than the parts. Adv Chronic Kidney Dis . 2014;21(4):333-337.

4. Harper JL, De Costa AM, Garrett-Mayer E, Sterba KR. Incorporating patient satisfaction metrics in assessing multidisciplinary breast cancer care quality. South Med J. 2015;108(6):372-376.

5. Litton G, Kane D, Clay G, Kruger P, Belnap T, Parkinson B. Multidisciplinary cancer care with a patient and physician satisfaction focus. $J$ Oncol Pract. 2010;6(6):e35-e37.

6. Normann B, Moe S, Salvesen R, Sorgaard KW. Patient satisfaction and perception of change following single physiotherapy consultations in a hospital's outpatient clinic for people with multiple sclerosis. Physiother Theory Pract. 2012;28(2):108-118.

7. Wetmore S, Boisvert L, Graham E, et al. Patient satisfaction with access and continuity of care in a multidisciplinary academic family medicine clinic. Can Fam Physician. 2014;60(4):e230-e236.

8. Cup EH, Pieterse AJ, Knuijt S, Hendricks HT, van Engelen BG, Oostendorp RA, van der Wilt GJ. Referral of patients with neuromuscular disease to occupational therapy, physical therapy and speech therapy: usual practice versus multidisciplinary advice. Disabil Rehabil. 2007;29(9):717-726.

9. Bungard TJ, Barry AR, Jones C, Brocklebank C. Patient satisfaction with services provided by multidisciplinary anticoagulation clinics. Pharmacotherapy. 2013;33(11):1246-1251.

10. Pinnington MA, Miller J, Stanley I. An evaluation of prompt access to physiotherapy in the management of low back pain in primary care. Fam Pract. 2004;21(4):372-380.

11. Turner MR, Kiernan MC. The standard of care in amyotrophic lateral sclerosis: a centralised multidisciplinary clinic encounter sets a new benchmark for a uniquely challenging neurodegenerative disorder. $J$ Neurol Neurosurg Psychiatry. 2015;86(5):481-482.

12. Stephens HE, Young J, Felgoise SH, Simmons Z. A Qualitative study of multidisciplinary ALS clinic use in the United States. Amyotroph Lateral Scler Frontotemporal Degener. 2015:17(1-2):55-61.

13. Berwick DM, Nolan TW, Whittington J. The triple aim: care, health, and cost. Health Aff (Millwood). 2008;27(3):759-769.

14. Abresch RT, Carter GT, Han JJ, McDonald CM. Exercise in neuromuscular diseases. Phys Med Rehabil Clin NAm. 2012;23(3):653-673.

15. McDonald CM. Clinical approach to the diagnostic evaluation of hereditary and acquired neuromuscular diseases. Phys Med Rehabil Clin NAm. 2012;23(3):495-563.

16. West AN, Lee RE, Shambaugh-Miller MD, et al. Defining "rural" for veterans' health care planning. J Rural Health. 2010;26(4):301-309.

17. Flanigan KM, Coffeen CM, Sexton L, Stauffer D, Brunner S, Leppert MF. Genetic characterization of a large, historically significant Utah kindred with facioscapulohumeral dystrophy. Neuromuscul Disord. 2001;11(6-7):525-529.
Journal of Multidisciplinary Healthcare

\section{Publish your work in this journal}

The Journal of Multidisciplinary Healthcare is an international, peerreviewed open-access journal that aims to represent and publish research in healthcare areas delivered by practitioners of different disciplines. This includes studies and reviews conducted by multidisciplinary teams as well as research which evaluates the results or conduct of such teams or health-

\section{Dovepress}

care processes in general. The journal covers a very wide range of areas and welcomes submissions from practitioners at all levels, from all over the world. The manuscript management system is completely online and includes a very quick and fair peer-review system. Visit http://www.dovepress.com/ testimonials.php to read real quotes from published authors. 